\title{
Does destination image influence the length of stay in a tourism destination?
}

\author{
LUIZ PINTO MACHADO
}

\begin{abstract}
Escola Profissional de Hotelaria e Turismo, Travessa Dos Piornais, São Martinho, 9000-246 Funchal, Madeira, Portugal. E-mail: luiz.machado@madeira-edu.pt.
\end{abstract}

\begin{abstract}
This paper analyses the relationship between the image of a destination and demand duration, focusing specifically on Madeira. A seemingly unrelated discrete-choice duration model is adopted, with data from a questionnaire survey undertaken in 2008 on a sample of homeward-bound foreign individuals departing from Madeira's Funchal Airport. The paper discusses the policy implications of the research findings.
\end{abstract}

Keywords: duration models; endogeneity; destination image; length of stay; Madeira

When deciding the length of stay, a tourist may be influenced by a variety of factors, including his or her personal characteristics and the destination's characteristics. Some of the latter, which contribute to the image that a tourist perceives of the destination, may be related directly to the length of stay that he or she plans for that destination. The more positive the ex ante image, the longer the length of stay planned (Chon, 1991; Baloglu and McCleary, 1999). Researchers usually analyse these two variables independently of each other, although they may be influenced by the same factors. However, observed and non-observed factors give rise to the expectation that these two processes are inextricably linked.

This paper examines the relationship between the destination image and the length of stay in a tourism destination, with specific reference to Madeira, using a sample of foreign tourists about to depart from the island at the end of their vacation. A Weibull survival discrete-choice duration model is adopted (Boehmke et al, 2006). Thus, we establish a statistical link between the length of stay and destination image by measuring the effect of observed and unobserved factors.

Our research was motivated by the following four points. First, survival models have proven to be particularly suited to the modelling and analysis of duration events (Hong and Jang, 2005; Gokovali et al, 2007; Barros et al, 2008, 2010). Second, destination image studies contribute to the elaboration of tourism policies based on quality and satisfaction (Baloglu and McCleary, 1999). 
Third, it is important for policy purposes to investigate how tourists decide on the duration of their stay and to what extent this is related to the destination's image. If we know the factors that explain, for a certain tourism destination, the length of stay and destination image covariates, we can then define policy prescriptions aiming to maximize the time tourists spend in the destination. Finally, the consequence of endogeneity between length of stay and destination image is taken into account in the present research. Ignoring such endogeneity can bias parameter estimates in an unknown direction, making conclusions drawn from them tenuous at best (Boehmke et al, 2006).

The paper contributes to the tourism literature, first, by analysing the determinants of the destination image and the length of stay of, in this instance, foreign tourists in Madeira. Secondly, it adopts a survival model with endogeneity, which is a novelty in the context of tourism economics. We are not aware of any research paper previously adopting survival models with endogeneity.

The paper is organized as follows. We first present the background arguments behind the research. We then present a review of the literature relevant to the present research and the adopted research methodology and design. The questionnaire, analysis, results and discussion are then presented in turn, followed finally by our overall conclusions.

\section{Background arguments}

The survival model estimated in this study to measure the length of stay in a tourist destination is based on the theory of consumer behaviour arising from Lancaster (1966) and the concept of hedonic prices (Rosen, 1974). Length of stay is a major aspect of demand and, therefore, part of demand management. The economic theory of consumer behaviour assumes that when faced with making a consumption decision, an individual aiming to maximize his or her utility, subject to budgetary restrictions, makes that decision based on prices and income (Varian, 1987). This traditional framework, however, does not allow for circumstantial conditions and social factors, which are known to play an important role in shaping tourism demand, given the composite or differentiated nature of the services that comprise a tourist destination. Moreover, it focuses on quantity, while the present research focuses on another aspect of demand: duration. Therefore, the demand for tourism is derived from the demand for the various goods and services offered by a tourism destination (Ben-Akiva and Lerman, 1985).

\section{Linking destination image and length of stay}

Image formation on a specific tourism destination starts when the individual plans the holiday and finishes when he or she departs from the destination (Chon, 1990, 1991; Baloglu and McCleary, 1999). Destination image will influence tourists in the process of choosing a destination, the length of stay in the destination, the subsequent evaluation of the holiday and their future intentions. Therefore, image formation and length of stay are defined simultaneously, but while the length of stay is established prior to the holiday, 
the destination image will change with the destination attributes, the quality of service and so on.

Existing studies have considered the effect of a variety of observed factors on both phenomena. Here, we wish to focus on the influence that unobserved factors might have once observed factors are controlled for. To delineate the two components, therefore, we refer to the portion of the destination image determined by such observed factors as the expected destination image; deviations from the expected destination image are based on unobserved factors and are referred to as unexpected or unanticipated. If unobserved factors systematically influence both destination image and length of stay, then these two variables are related. In addition, potentially unobserved elements that may influence both factors are the time the tourist has available, whether or not he or she is to be accompanied by the family and whether there are any health concerns. All these factors affect the destination image and the length of stay, generating endogeneity.

This dictates the use of an empirical model that permits the testing of hypotheses on observed and unobserved factors. Existing published papers only allow us to account for the impact of observed factors on destination image and length of stay, but leave open the question of how unobserved factors influence both.

\section{Literature review}

Two lines of research are reviewed in the present work. First, survival models and second, destination image models.

Studies on duration models in tourism are rare. Recently, Barros et al (2010) have analysed the length of stay of golf tourists in the Algarve, Portugal, allowing for heterogeneity and sample selection. The Cox model, the Weibull model, the Weibull with heterogeneity and the Weibull with sample selection were adopted. The covariates were nationalities, socio-economic characteristics, golf experience and habits, motivation, hotel and travel facilities, information and golf attributes. The main conclusions were that the length of stay depended on multiple covariates such as older, well-educated German, British and French golf enthusiasts, standards of service and hospitality provided by the hotel personnel and golfers' activities in the sporting, cultural and entertainment domains. A general conclusion was that tourists seemed to behave similarly in different contexts relative to some variables, but not necessarily relative to others. Based on the heterogeneity detected in the sample, the idea of a homogeneous tourist population should be abandoned, even for such a destination as the Algarve. This result implies that each destination must be analysed individually and independently of each other. Furthermore, sample selection which is inherent to questionnaire data has to be taken into account when using survival models.

Barros et al (2008) analysed the length of stay of Portuguese tourists in South America with alternative survival models. The Cox model, the Weibull model, the logistic model and the Weibull with heterogeneity were adopted. The covariates used were budget, destination attributes, socio-demographic characteristics, previous visits, temporal constraints and the frequency of travel. 
The main conclusion was that the length of stay depended on multiple determinants and was specific to each tourism destination. Menezes et al (2008) analysed the length of stay of tourists in the Azores islands with a Cox proportional hazard model and using questionnaire data. The covariates used were socio-demographic profiles, trip attributes, sustainability practices and destination image attributes. The main conclusion was that the covariates explained the length of stay and the repeat visitor was particularly important in this context.

Martinéz-Garcia and Raya (2008) analysed low-cost tourists' length of stay in Spain with log-logistics and Cox survival models. Questionnaire data were used. The covariates used were nationality, socio-economic characteristics, occupation, reason for travel, type of accommodation, organized travel, travelling with family, high season and geographical area. The main conclusion was that the hypothesis of proportionality was not fulfilled and, therefore, an accelerated survival model was adopted. Moreover, only some covariates were statistically significant, namely, tourists' nationality, age, level of education, type of education, type of accommodation, the season and the geographical area.

Gokovali et al (2007) applied survival analysis to model the length of stay of tourists in Bodrum, Turkey, using two survival model specifications: the Cox model and the Weibull model. The covariates used were nationality, age, job type, socio-economic characteristics, package vacation type (full-board, bed and breakfast, full-package), previous visits, quality, level of hospitality, attractiveness, nightlife, accomodation, image, promotion and publicity and recommendation. The main conclusion was that the covariates explained the length of stay. Hong and Jang (2005) analysed the duration of visits to a casino with survival models.

Kaniovski et al (2008) analysed firm survival in the Austrian accommodation sector with a gamma duration model. They concluded that larger size and market share increased survival, while turnover and age decreased survival.

According to the author's best knowledge, the present study is the first to adopt this technique in tourism allowing for endogeneity.

Analysis of destination image is a well-established line of research in tourism economics (Woodside and Lysonski, 1989; Chon, 1990; Echtner and Ritchie, 1991; Milman and Pizam, 1995; Baloglu and McCleary, 1999; Castro et al, 2007). According to this research, tourists' behaviour is expected to be partly conditioned by their perceived image of a destination. The influence of image on the destination choice process has been studied by various authors (for example, Goodall and Ashworth, 1988; Gartner, 1989; Crompton and Ankomah, 1993), concluding that destination image exerts a positive influence on perceived quality and satisfaction.

Whilst we observe that destination image and length of stay have been analysed independently of each other, it is also possible to define them simultaneously. The length of stay is measured in the usual way, that is, the number of days of vacation in the destination, but destination image is measured by asking the tourists whether the a priori image has improved or deteriorated by the end of the holiday. We conclude that this is an unorthodox way of measuring destination image, which is usually measured by a large number of destination and individual characteristics. 


\section{Research design}

\section{Hypotheses}

As mentioned above, the duration of a holiday can be explained by several factors. Hence, the survey questionnaire gathered data pertaining to: (i) sociodemographic characteristics; (ii) nationalities; (iii) expenditure; (iv) destination attributes; (v) previous holidays in the destination; and (vi) quality. The survey data gathered on these characteristics was used to test the following hypotheses:

Hypothesis 1 - the length of stay and image are defined simultaneously. The formation of an image of a specific tourism destination starts when the individual is planning the holiday and ends when he or she departs from the destination (Chon, 1990, 1991; Baloglu and McCleary, 1999). Destination image will influence tourists in the process of choosing a destination, the subsequent evaluation of the trip and their future intentions.

Hypothesis 2 - effect of socio-demographic characteristics on length of stay. The length of stay is a function of individual socio-demographic characteristics such as age, gender and level of education (Goodall and Ashworth, 1988; Woodside and Lysonski, 1989; Weaver et al, 1994; Zimmer et al, 1995).

Hypothesis 3 - effect of nationality on length of stay. The length of a vacation is a function of the nationality of the tourist, reflecting his or her income. This is a traditional hypothesis in tourism demand models.

Hypothesis 4 - effect of expenditure on length of stay. The length of a vacation is a function of the individual's expenditure. This is a traditional hypothesis in tourism demand models in which price, income and budget constraints define the frontier of consumption possibilities for travel (Hay and McConnel, 1979; De la Vina and Ford, 2001; Nicolau and Más, 2005).

Hypothesis 5 - effect of destination attributes on length of stay. The length of stay is a function of a destination's atractiveness in terms of attributes, such as wine production. Madeira has long been established and recognized as a producer of fine wines; therefore, wine is an important characteristic of this destination.

Hypothesis 6 - effect of previous visits on length of stay. The length of stay is influenced by previous holidays in the destination. Festinger (1954) noted that satisfaction in relation to the destination influenced future choices. Beerli and Martín (2004) demonstrated that sun-and-sand destinations with a favourable image had a high level of repeat visitors. Kozak (2001) demonstrated that overall satisfaction and the number of previous visits considerably influenced the intention to return, particularly with regard to mature destinations. Kozak (2003) also concluded that destination attributes influenced future behavioural intentions and satisfaction.

Hypothesis 7 - effect of quality on length of stay. The length of stay is a function of the overall quality of service. Overall quality is a principal determinant of 
tourists' length of stay. Roca et al (2009) analysed quality in beach tourism, concluding that two cluster groups, that is, satisfied and demanding beach users, were identified, signifying that there were always satisfied and dissatisfied tourists in any tourism destination, as well as demanding and non-demanding tourists.

Hypothesis 8 -effect of quality on destination image. Destination image is a function of the quality of services in the destination. Kozak (2003) concluded that destination attributes influenced future behavioural intentions and satisfaction. As destination image is a subjective attribute, quality and destination image may be related.

Hypothesis 9 - effect of satisfaction on destination image. Destination image is a function of the satisfaction experienced in the destination. Festinger (1954) noted that satisfaction in relation to the destination influenced future choices. Kozak (2001, 2003) demonstrated that overall satisfaction and the number of previous visits considerably influenced the intention to return, in particular for mature destinations. Therefore, satisfaction may affect the length of stay.

Hypothesis 10 - effect of health concerns on destination image. Destination image is a function of preoccupations over health risks. Health concerns affect the destination image positively when the image incorporates a health orientation, as is the case with Madeira. The usually small differences between maximum and minimum temperatures, as well as the island's average temperatures, are considered good for health (Oliveira and Pereira, 2008).

Hypothesis 11 - effect of destination characteristics on destination image. Destination image is a function of destination characteristics such as wine, casinos and climate. Woodside and Lysonski (1989) argue that a destination's image and its choice are influenced by destination attributes such as those considered in this study.

Hypothesis 12 - effect of expenditure on destination image. Destination image is a function of the expenditure. Price and budget constraints are major influences on destination choice (Barros et al, 2008). Although most researchers use price to explain the choice of destination (De la Vina and Ford, 2001), others consider income (Hay and McConnel, 1979; Nicolau and Más, 2005). In this paper, we rely on holiday expenditure as a proxy for income to test this hypothesis.

\section{Methodology}

In this study, the vacation length of stay is analysed using a survival modelling approach (Allison, 1984; Cox and Oakes, 1984; Yamaguchi, 1991; Hosmer and Lemeshow, 1999; Kalbfleich and Prentice, 2002; Cleeves et al, 2002). Survival analysis, also known as duration models, measures the duration of an event, which is the time elapsed until a certain event occurs or is completed. The length of a vacation is an example of a duration event. The use of survival models to model duration is based on the fact that the error distribution in 
this context, by necessity, must be skewed to the right (Hosmer and Lemeshow, 1999). The survival model regresses the duration of an activity on covariates. Such models are currently adopted in economics on the basis of two facts: (i) time, as a dependent variable, is strictly positive and, therefore, the use of the traditional Gaussian distribution is not adequate to capture the characteristics of the time variable; and (ii) in clinical trials, censoring occurs when an individual participant in the initial phase of the study subsequently dies. Survival analysis can accommodate the loss of observations adequately when censoring occurs.

Since traditional regression models are unable to overcome this issue, survival models, such as the Cox model and the Weibull model, have appeared (Hosmer and Lemeshow, 1999). The dependent variable of interest is the number of days that the respective tourist spends on vacation, which is regressed against covariates. Examples of the application of survival modelling in social and economic sciences are the 'survival' of marriages, high school drop-out rates (that is, the time until dropping out), staff turnover in organizations, duration of unemployment, the 'survival' of new businesses or the 'survival' lifetimes of products such as automobiles. In quality control research, it is common practice to study the survival of parts under stress (failure time analysis).

Three issues must be addressed when analysing survival models: (i) identification of the data set (that is, cross-section versus panel data); (ii) censoring of the data; and (iii) sample selection. With regard to the first issue, the present study adopted a cross-sectional approach. Therefore, time-invariant modelling, known as proportional hazard models, was adopted (Wooldridge, 2002). In terms of censoring, Gokovali et al (2007) concluded that questionnaire data were uncensored because the tourists were surveyed at the end of their holidays. A survival time is described as censored when there is a follow-up time, but the event has not yet occurred or is not known to have occurred. For example, if the length of time in a beach resort is being studied and the tourist is still on holiday at the end of the study, then the start of the holiday is observed, but the end time would be censored. If a tourist for some reason drops out of a study before the end of the study period, then that tourist's follow-up time would also be considered to be censored since it is unobserved. Since our questionnaire surveyed tourists who had completed their holidays and were about to board their flights home, the length of stay was completely determined. With regard to the third issue, ignoring sample selection may bias the results (Cameron and Triverdi, 2005).

\section{Endogeneity in the length of stay}

When there is endogeneity, the estimated parameters obtained by the traditional survival model (Gokovali et al, 2007) are not consistent, either because of measurement errors in the duration variable, or because the explanatory variables are correlated with the unobserved disturbances in the equation. The tourist's length of stay is assumed to be independent of the covariates that explain the length of stay. However, in the length of stay equation, a relevant variable may be missing or may be defined simultaneously with the length of stay, introducing endogeneity into the model. Boehmke et al (2006) propose a seemingly unrelated discrete-choice duration (SUDCD) 
survival model. The Weibull SUDCD estimator has two components. The first component is a standard exponential duration equation, which generates data according to the following process: $d_{i}=\exp \left(x_{i} b\right) e_{i}$, where $x_{i}$ is a vector of explanatory variables and $e_{i}$ follows an exponential distribution. The second component is the exponential discrete-choice equation. The likelihood function is the following (Boehmke et al, 2006):

$$
L(\beta, \gamma, p, \alpha \mid X, W, L S, D I)=\prod_{i=1}^{n} p \lambda_{2 i}^{p} d_{i}^{p-1} \exp \left(-\left(\lambda_{2 i} d_{i}\right)^{p}\right)\left(1-\pi_{i}^{1}\right)^{1-v_{i}}\left(\pi_{i}^{1}\right)^{v_{i}}
$$

where $\beta, \gamma, p$ and $\alpha$ are parameters to be estimated, $X$ is a vector of explanatory variables, $W$ is the Weibull distribution, $L S$ is the length of stay and $D I$ is the destination image; $p$ is the Weibull distribution shape parameter when the error term follows an exponential distribution; $\lambda 2 i=\exp \left(-x_{i} b\right) ; d_{i}=\exp \left(x_{i} b\right) e i$ and $\pi_{i}$ is the conditional probability that the tourist registers a perceived improvement in the destination image.

\section{Survey and study context}

The research study was undertaken in 2008. Tourists waiting to board their flights home at Madeira Funchal Airport were randomly invited to take part in a questionnaire survey. The sample was defined on the basis of the confidence interval approach (Burns and Busch, 1995). The formula used to estimate a 95\% confidence level was:

$$
n=\frac{z^{2}(p q)}{e^{2}}=\frac{1.95^{2}(0.5 \times 0.5)}{0.5^{2}}=385
$$

where $z$ was the standard error associated with the chosen level of confidence (95\%); $p$ was the estimated variability in population (50\%); $q=1-p$; and $e$ was the acceptable sample error $\pm 5 \%$ (desired accuracy 95\%). The amount of variability in the population is estimated to be $50 \%$, which is widely used in social research (Chi and $\mathrm{Qu}, 2008)$.

The interviewer approached the randomly selected tourist in the departure lounge while he or she was waiting to be called for embarkation. Budgetary constraints restricted the total number of questionnaires available to 550, assuming a response rate of $80 \%$ and the number of unusable questionnaires at $10 \%(385 / 0.7=550)$. The number of questionnaires answered was 498 , but, on inspection, only 346 were found to be usable, due to errors and incomplete responses.

The general characteristics of these respondents revealed that $52 \%$ were male and the average age was 33. On average, they were middle-class, middle income. Other characteristics of the sample are summarized in Table 1, which also broadly indicates the items contained in the questionnaire and presents the data used.

The survey contained three types of variables: dichotomous variables, continuous variables and qualitative variables (using a 5-point Likert scale). The set of explanatory variables considered in this study sought to capture the key determinants of the holiday-choice decision process, based on the theoretical framework and the literature review (Barros et al, 2008). 


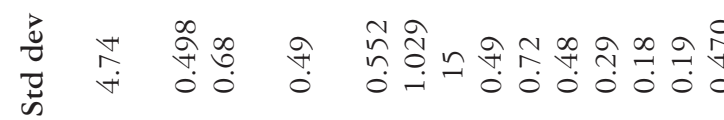

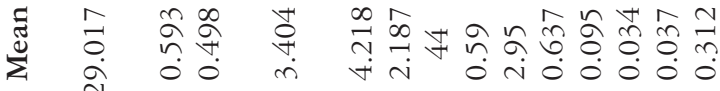

胥

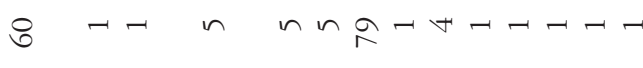

$\sum^{\pi}$

䛼

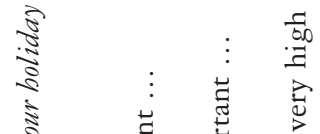

$\ddot{\circ} \ddot{\circ} \ddot{8}$

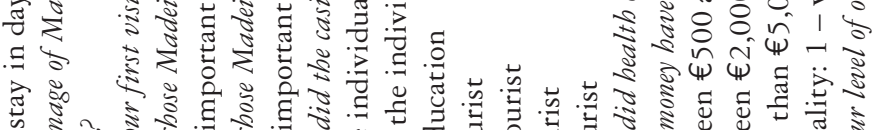

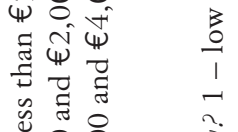

188

$\stackrel{2}{2} \approx \hat{\omega} \omega$

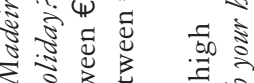
-

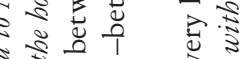

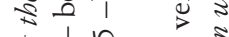

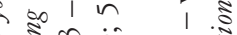

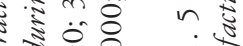
$+8 m$ $\rightarrow \widetilde{m} 3$ है

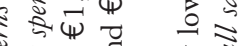
₹

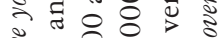

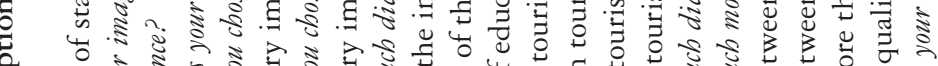

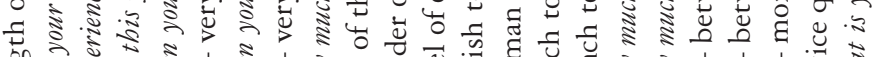

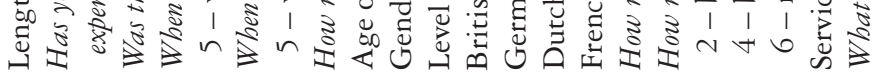

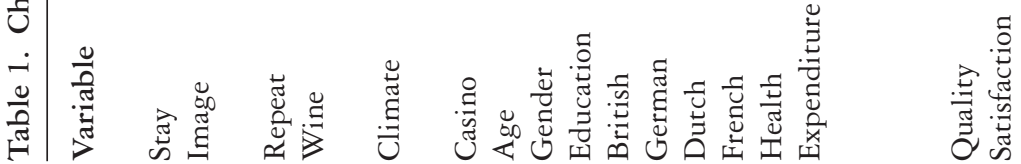


Table 2. Survival model results.

\section{Separate equations}

Length of stay

Repeat

Wine

Age

Gender

Education

British

German

Dutch

French

Expenditure

Quality

Constant

Destination image

Return

Quality

Satisfaction

Health

Wine

Climate

Casino

Expenditure

Constant

Correlation $\left(Z^{-1}(a)\right)$

Constant

Return

Duration dependence $(\ln (p)$ or $\ln (r))$

Number of observations

Log likelihood

\section{$0.012 *$}

$0.832 *$

$0.512 *$

$-0.452 * *$

$0.813^{*}$

$0.008 *$

0.123

$0.019 * *$

3.413

$-$

$-$

$1.195 *$

442

$-204.465$

Std
error
Weibull SUDCD
model
(simultaneous
equations)

$\begin{array}{llll}-0.258 & 0.463 & -0.210 & 0.532 \\ 0.213 * & 0.035 & 0.218^{*} & 0.069 \\ 0.030 * & 0.012 & 0.045^{*} & 0.025 \\ 0.325 & 0.631 & 0.216 & 0.732 \\ 0.096 & 0.390 & 0.075 & 0.673 \\ 3.949 * & 1.088 & 2.227 * & 0.974 \\ 2.731 * & 0.881 & 2.019 & 0.734 \\ 3.240 * & 1.083 & 2.184 & 0.893 \\ 3.404 * & 1.133 & 2.112 & 0.734 \\ 0.068 * & 0.316 & 0.052 & 0.316 \\ 0.424 * & 0.071 & 0.256 & 0.052 \\ -3.993 * & 0.603 & -3.134 & 0.562\end{array}$

0.231

0.421

0.522

0.647

0.397

0.315

0.123

0.279

3.331
Std

error

0.562

$\begin{array}{ll}0.052 * & 0.373 \\ 0.673 * & 0.231 \\ 0.419 * & 0.432 \\ -0.521 * * & 0.743 \\ 0.716 * & 0.237 \\ 0.021 * & 0.134 \\ 0.152 & 0.134 \\ 0.023 * * & 0.453 \\ 3.410 & 2.219\end{array}$

\subsection{7}

0.885

$0.213^{*}$

0.213

1.162*

0.141

Note: All models were estimated in Stata 10. *Significant parameters at $1 \%$.**Significant parameters at $5 \%$.

In order to evaluate the degree of correlation among the explanatory variables, which can cause multicollinearity, we investigated the correlation matrix, concluding that it was low among the variables used in the analysis.

\section{Results}

Table 2 presents the results of the estimated duration models. We present the Weibull model without sample selection and the Weibull model with sample selection for the purpose of comparison. The dependent variable is the length of stay, measured in days, of tourists in Madeira Funchal Airport, homewardbound from their vacations. 
In the two models, the results are similar in their main effects. Given the model specification, positive values for the parameters implies that the length of stay increases with increasing values in the respective variable. A negative value for the parameters implies a negative relationship. The results across the two models demonstrate that the parameters have the different signs for endogenous variables and the same signs but different values for exogenous variables, revealing the importance of controlling sample selection in survival models.

On the basis of the log-likelihood statistic, the Weibull model with endogeneity describes the data better. The rationale for this result is that endogeneity represents unobserved characteristics that influence the conditional probability of the length of stay and destination image in Madeira Island which are not measured or observed and therefore not taken into account in the measurement errors of the variables (Boehmke et al, 2006).

Taking as reference the simultaneous equation Weibull model, as hypothesized, the socio-demographic variables age, gender and education have a positive effect on the hazard of length of stay, which means that older, male and more educated tourists tend to stay longer. Moreover, different nationalities have different impacts on hazards of length of stay. Furthermore, expenditure has a negative impact on hazards of length of stay, which means that those tourists who spend more money tend to have shorter holidays, which is rational for tourists with budgetary constraints.

In addition, some destination attributes, such as the old and well-established reputation for wine, have a positive impact on the hazard of length of stay, signifying that this attribute increases the length of stay in Madeira.

Previous visits has a positive effect on the hazard, signifying that Madeira enjoys a substantial number of tourists whose satisfaction levels give rise to repeat holidays. On the other hand, hotel quality has a negative effect on the hazard, since high quality is expensive.

Relative to destination image, it is verified that all factors with the exception of health have a positive effect on the hazard. The results for repeat, quality and satisfaction are intuitive, signifying that returning tourists have the most positive image of the destination, that quality improves the destination image and satisfaction is translated into destination image. The consumption of wine, the destination characteristic climate and the presence of casinos improve the destination image. The higher the expenditure, the more positive the destination image. Health concerns have a negative effect on destination image.

\section{Discussion}

The general conclusion is that the destination image and length of stay evolve simultaneously in Madeira Island, signifying that the the higher the destination image, the higher the length of stay. Moreover, the results support the majority of the hypotheses and are broadly intuitive, signifying that older, more educated, male, British, German, Dutch and French tourists in Madeira are more likely to stay the longest. In fact, all the variables with the exception of repeat increase the length of stay. 
Morever, all variables increase the destination image, with the exception of health concerns. These are intuitive results, signifying that illness affects the destination image negatively and repeat visits affect the length of stay negatively.

In terms of policy implications, the results suggest that tour operators seeking to attract tourists to Madeira for extended lengths of stay should target the more affluent individuals. This market segment consists of older, more educated, male German tourists. Moreover, the destination image is nurtured during the visit and so should also be managed appropriately.

The research found that a demand model that accounted for sample selection was superior to models that did not assume it. With regard to the managerial implications, research which provides a deeper insight into the driving motives behind tourist choice behaviour can therefore support the development of marketing strategies.

The sample employed in this research was limited to a single destination and a limited number of months; thus, the conclusions cannot be generalized to other tourism contexts. However, since this research was an exploratory study designed to investigate and demonstrate the suitability of survival modelling as a means of developing a deeper insight into the factors which drove holiday length of stay decision making, this limitation was not critical.

Survival modelling has been shown to be a useful technique for this purpose. How do these findings compare with previous research? The results confirm that age and income increase the length of stay in all cited studies. The Gokovali et al (2007) study, which used the same method as the present work, found that nationality was the main explanatory variable. In terms of other variables common across studies, the general conclusion is that tourists seem to behave similarly in different contexts relative to age and budget. In contrast, differences across studies are evident with respect to the role of a number of other variables. Therefore, there is a need for further research to apply survival modelling in analysing the determinants of length of stay in a variety of other contexts. As the body of research into the determinants of length of stay expands, at some point in time it may become possible to investigate the differences in results across studies using meta-analytical techniques.

\section{Conclusion}

This paper has analysed the length of stay of European tourists taking holidays in Madeira. Two duration models were presented for comparative purposes; namely, the parametric Weibull model without sample selection and the Weibull model with sample selection. The Weibull model with sample selection achieved superior performance on the basis of the log-likelihood statistics. It is concluded that the length of stay is related positively to age, gender, education, German, wine and previous visit. The length of stay is related negatively to other variables including British, Dutch and French, expenditure and quality. These results are intuitively consistent with the concept that economic affluence influences the length of stay. 


\section{References}

Allison, P.D. (1984), Event History Analysis, Sage, Beverly Hills, CA.

Baloglu, S., and McCleary, K.W. (1999), 'A model of destination image formation', Annals of Tourism Research, Vol 26, No 4, pp 868-897.

Barros, C.P., Correia, A., and Crouch, G. (2008), 'Determinants of the length of stay in Latin American tourism destinations', Tourism Analysis, Vol 13, No 4, pp 329-340.

Barros, C.P., Butler, R., and Correia, A. (2010), 'The length of stay of golf tourism: a survival analysis', Tourism Management, Vol 31, No 1, pp 13-21.

Beerli, A., and Martín, J. (2004), 'Tourists' characteristics and the perceived image of tourist destinations: a quantitative analysis - a case study of Lanzarote, Spain', Tourism Management, Vol 25, pp 623-636.

Ben-Akiva, M.E., and Lerman, S. (1985), Discrete Choice Analysis: Theory and Applications to Travel Demand, MIT Press, Cambridge, MA.

Boehmke, F., Morey, D.S., and Shannon, M. (2006), 'Selection bias and continuous-time duration models', American Journal of Political Science, Vol 50, No 1, pp 192-207.

Burns, A.C., and Bush, R.F. (1995), Marketing Research, Prentice-Hall, NJ.

Cameron, A.C., and Triverdi, P.K. (2005), Microeconometrics: Methods and Applications, Cambridge University Press, Cambridge, New York.

Castro, C.B., Armario, H.M., and Ruiz, D.M. (2007), 'The influence of market heterogeneity on the relationship between a destination's image and tourists' future behaviour', Tourism Management, Vol 28, No 1, pp 175-187.

Chi, C.G.Q., and Qu, H. (2008), 'Examining the structural relationships of destination image, tourist satisfaction and destination loyalty: an integrated approach', Tourism Management, Vol 29, pp 624-636.

Chon, K.S. (1990), 'The role of destination image in tourism. A review and discussion', Tourist Review, Vol 45, No 2, pp 2-9.

Chon, K.S. (1991), 'Tourism destination image modification process', Tourism Management, Vol 12, pp $68-72$.

Cleeves, M.A., Gould, W.W., and Gutierrez, R.G. (2002), An Introduction to Survival Analysis Using Stata, Stata Press, College Station, TX.

Cox, D.R., and Oakes, D. (1984), Analysis of Survival Data, Chapman and Hall/CRC Press, London.

Crompton, J.L., and Ankomah, P. (1993), 'Choice set propositions in destination decisions', Annals of Tourism Research, Vol 20, pp 461-476.

De la Vina, L., and Ford, J. (2001), 'Logistic regression analysis of cruise vacation market potential: demographic and trip attribute perception factors', Journal of Travel Research, Vol 39, No 4, pp 406-410.

Echtner, C.M., and Ritchie, J.R.B. (1991), 'The meaning and measurement of destination image', The Journal of Tourism Studies, Vol 2, No 2, pp 2-12.

Festinger, L. (1954), 'A theory of social comparison processes', Human Relations, Vol 7, pp 117-140.

Gartner, W.C. (1989), 'Tourism image: attribute measurement of state tourism products using multidimensional scaling techniques', Journal of Travel Research, Vol 28, No 2, pp 16-20.

Gokovali, U., Bahar, O., and Kozak, M. (2007), 'Determinants of length of stay: a practical use of survival analysis', Tourism Management, Vol 28, No 3, pp 736-746.

Goodall, B., and Ashworth, G., eds (1988), Marketing in the Tourism Industry. The Promotion of Destination Regions, Routledge, London.

Hay, M., and McConnel, K. (1979), 'An analysis of participation in non-consumptive wildlife recreation', Land Economics, Vol 55, pp 460-471.

Hong, S.K., and Jang, H. (2005), 'Factors influencing purchasing time of a new casino product and its managerial implications: an exploratory study', Journal of Travel Research, Vol 43, pp 395403.

Hosmer, D.W., and Lemeshow, S. (1999), Applied Survival Analysis: Regression Modelling of Time to Event Data, John Wiley and Sons, New York.

Kalbfleich, J.D., and Prentice, R.L. (2002), The Statistical Analysis of Failure Time Data, 2nd edition, John Wiley and Sons, New York.

Kaniovski, S., Peneder, M., and Smeral, E. (2008), 'Determinants of firm survival in the Austrian accommodation sector', Tourism Economics, Vol 14, No 3, pp 527-543.

Kozak, M. (2001), 'Repeaters' behaviour at two distinct destinations', Annals of Tourism Research, Vol 28, No 3, pp 784-807. 
Kozak, M. (2003), 'Measuring tourist satisfaction with multiple destination attributes', Tourism Analysis, Vol 7, pp 229-240.

Lancaster, K.J. (1966), 'A new approach to consumer theory', Journal of Political Economy, Vol 74, No 2, pp 132-157.

Martinéz-Garcia, E., and Raya, J.M. (2008), 'Length of stay for low cost tourism', Tourism Management, Vol 29, No 6, pp 1064-1075.

Menezes, A.G., Moniz, A., and Vieira, J.C. (2008), 'The determinants of length of stay of tourists in the Azores', Tourism Economics, Vol 14, pp 205-222.

Milman, A., and Pizam, A. (1995), "The role of awareness and familiarity with a destination: the central Florida case', Journal of Travel Research, Vol 33, No 3, pp 21-27.

Nicolau, J., and Más, F. (2005), 'Stochastic modelling: a three-stage tourist choice process', Annals of Tourism Research, Vol 32, pp 49-69.

Oliveira, P., and Pereira, P.T. (2008), 'Who values what in a tourism destination? The case of Madeira Island', Tourism Economics, Vol 14, No 1, pp 155-168.

Roca, E., Villares, M., and Ortego, M.I. (2009), 'Assessing public perceptions on beach quality according to beach users' profile: a case study in the Costa Brava (Spain)', Tourism Management, Vol 30, No 4, pp 598-607.

Rosen, S. (1974), 'Hedonic prices and implicit markets: products differentiation in pure competition', Journal of Political Economy, Vol 82, pp 34-35.

Varian, H.R. (1987), Intermediate Microeconomics: A Modern Approach, W.W. Norton and Co, New York.

Weaver, P., McCleary, K., Lepisto, L., and Damonte, L. (1994), 'The relationship of destination selection attributes to psychological, behavioural and demographic variables', Journal of Hospitality and Leisure Marketing, Vol 2, pp 93-109.

Woodside, A., and Lysonski, S. (1989), 'A general model of travel destination choice', Journal of Travel Research, Vol 27, No 4, pp 8-14.

Wooldridge, J.F. (2002), Econometric Analysis of Cross Section and Panel Data, MIT Press, Cambridge, MA.

Yamaguchi, K. (1991), Event History Analysis, Sage, Newbury Park, CA.

Zimmer, Z., Brayley, R., and Searle, M. (1995), 'Whether to go and where to go: identification of important influences on seniors' decisions to travel', Journal of Travel Research, Vol 33, No 3, pp $\underline{3-10 .}$ 